Research article

\title{
An inoculum of endophytic fungi for improved growth of a traditional rice variety in Sri Lanka
}

\author{
W.A.D.K. Wijesooriya and N. Deshappriya* \\ Department of Botany, Faculty of Science, University of Kelaniya, Kelaniya, Sri Lanka \\ *Corresponding Author: deshapri@kln.ac.lk \\ [Accepted: 12 September 2016]
}

\begin{abstract}
Use of chemical fertilizers and pesticides in rice cultivation has incurred many environmental and health problems in Sri Lanka. Therefore, there is renewed interest in cultivating traditional rice varieties as they are more amenable to organic farming practices. However, as the yield of these varieties is comparatively low, strategies to enhance their performance should be investigated. As endophytes of plants are reported to promote growth and yield of a number of crop varieties, this study was aimed at studying the endophytic fungal assemblage present in the traditional rice variety Kuruluthuda with a view to evaluate their capacity to enhance plant growth and yield. Twenty seven endophytic fungal species were isolated from different parts of Kuruluthuda rice plants collected from a paddy field cultivated using organic fertilizers in the Gampaha district, Sri Lanka. Two frequently isolated endophytic fungal spp. i.e. Acremonium and Arthrobotrys (frequencies of isolation $60 \%$ and $38.6 \%$ respectively) were introduced separately and in combination torice seedlings using spore suspension and plate methods to determine their effect on growth and yield under green house and field conditions. All endophyte inoculated plants showed a significant difference $(\mathrm{P} \leq 0.05)$ in plant growth (height, fresh weight and dry weight), number of tillers and yield when compared withnon-inoculated plant sunder both green house and field conditions. The effect of Acremonium and Arthrobotrys when introduced in combination showed a significant difference $(\mathrm{P} \leq 0.05)$ in the fresh weight, dry weight, tiller number and yield (weight of seeds harvested) when compared to their individual effects under field conditions which indicates that the two endophytes in combination can be used as a better inoculum to improve biomass and yield of the plants of rice variety tested. This is the first report of the endophytic mycoflora of the rice variety Kuruluthuda and their potential use for growth promotion and yield enhancement.
\end{abstract}

Keywords: Fungal endophytes - Acremonium - Arthrobotrys - Kuruluthuda - Growth enhancement.

[Cite as: Wijesooriya WADK \& Deshappriya N (2016) An inoculum of endophytic fungi for improved growth of a traditional rice variety in Sri Lanka. Tropical Plant Research 3(3): 470-480]

\section{INTRODUCTION}

Rice (Oryza sativa L.) is the staple food of a large part of the world population (FAO 1994). Improvement of rice grain yield has been dependent on the introduction of new high yielding varieties that are heavily dependent on the use of chemical fertilizers and pesticides. The need for long term, indiscriminate application of chemical fertilizers has led to hazardous influences on the environment as well as on human and animal health. Traditional rice varieties are highly amenable to organic farming practices that cause minimum damage to the environment and sustain soil health (Rathnabharathi 2009). Therefore, there is renewed interest in cultivating traditional rice varieties combined with organic farming practices. However, these varieties are known to be low producers of yield and thus their performance has to be improved to meet the demand of the highly expanding population. Recent studies aimed at improving the productivity of plants using alternative cultivation practices have focused on the possibility of using microorganisms to increase root growth and nutrient uptake of plants, fix nitrogen as well as decrease plant stress and disease incidence (Montesinos 2003).

Endophytes are microorganisms that can colonize internal plant tissues without causing apparent harm to the host (Petrini 1991). They are symbionts in plants and benefit the plant by enhancing growth directly by releasing 
phyto-hormones (i.e. auxins, giberallin and cytokinin) which are biosynthesized through their own pathways (Contreras-Cornejo 2009, You et al. 2012). These additional concentrations of hormones improve root and shoot biomass and reinforce the root system of plants which facilitates the acquisition of mineral nutrients from the soil (Feng et al. 2000) and enable plant roots to increase nitrogen and phosphorus uptake (Ryan et al. 2008). Indirectly, they increase the availability of the nutrients in the rhizosphere by mobilization of phosphate from organic phosphate sources (Tarafdar \& Claassen 1998) and producelow molecular weight metabolites (i.e. mycotoxins, altechromones and flavonoids) which are required for the normal functioning of plants under adverse conditions (Strobel 2003).

Diazotrophic bacterial and actinomycete populations of rice are reported to promote plant growth promotion and to possess the potential for nitrogen fixation and disease resistance (Barraquio et al. 1997, Tian et al. 2004). Fungal endophytes also have been detected in cultivated rice and they have shown to possess antagonistic or plant growth stimulating properties (Yuan et al. 2009, Naik et al. 2009). Previous studies in Sri Lanka have shown that some endophytes present in the traditional rice varieties Suwandel, Kaluheenati and Herath Banda have the ability to increase the growth of plants significantly (Atugala \& Deshappriya 2015, Ponnawila \& Deshappriya 2014). However, the endophytic fungal assemblage of the rice variety Kuruluthuda and their effect on plant growth and yield has not been reported in Sri Lankapreviously.

Therefore, the present study was carried out with the objectives:

- To isolate the endophytic fungal assemblage present in different plant parts of the rice variety Kuruluthuda.

- To develop method(s) of introducing endophytic fungi into seedlings.

- To evaluate the effect of the most frequently isolated fungal species on the performance of plants under green house and field conditions with a view to develop an inoculum for improved plant growth and productivity.

\section{MATERIALS AND METHODS}

\section{Sample collection and microscopic observation of roots}

Nine week old healthy, intact plants of the traditional rice variety Kuruluthuda were randomly collected from a field treated with organic fertilizers at Eldeniya, Sri Lankaduring the Maha season (September to February) and transported to the laboratory in clean polythene bags. Roots were cut into $7 \mathrm{~cm}$ long pieces and washed under running tap water for 20 minutes. Squashed preparations of root segments were observed under the light microscope and the presence of root inhabiting endophytic fungi was confirmed by trypan blue staining method (Yuan et al. 2009).

\section{Isolation and identification of endophytic fungi of therice variety Kuruluthuda}

Leaf pieces stem pieces, root segments and seeds of Kuruluthuda were used to isolate endophytic fungi. Each plant part was cleaned separately by rinsing under running tap water for $10-15 \mathrm{~min}$ and the cleaned plant parts were surface sterilized using the sterilization protocols reported previously (Atugala \& Deshappriya 2015).

After treatments with surface sterilizing agents, each plant part and seeds were washed with three consecutive changes of sterilized distilled water (SDW). The edges of the surface sterilized leaf, stem and root segments were trimmed and twenty five pieces of each of the plant parts and seeds were transferred aseptically into petri plates containing Malt Extract Agar (MEA) supplemented with tetracycline (50 mg. $\mathrm{l}^{-1}$ ). After 10 days incubation at room temperature $(\mathrm{RT})\left(30^{\circ} \mathrm{C}\right)$, endophytic fungal speciesthat grew out were subcultured onto fresh Potato Dextrose Agar (PDA) plates supplemented with tetracycline $\left(50 \mathrm{mg} .1^{-1}\right)$. Pure cultures of each isolated colony was obtained by hyphal tip method (Tutte 1969) and stored at $4^{\circ} \mathrm{C}$. The fungal cultures were identified based on morphological characters (i.e. features of hyphae and sporulating structures, colony morphology, texture and color) to genus level using standard keys of identification (Domschet al. 1993).

Isolation frequencies and percentages of dominant fungi were calculated as following (Fisher \& Petrini 1991, Goveas et al. 2011):

Isolation frequency $=($ Total number of isolates yielded in a given trial/ Total number of sample segments in the same trial) $\times 100$

Percentage dominance $=($ Number of isolates collected from the samples/ Total number of leaf/stem/root/seed samples) $\times 100$ 


\section{Inoculation of endophytic fungal species into seedlings}

The effect of most frequently isolated fungal endophytes i.e. Acremonium and Arthrobotrys on rice plant growth and yield was determined by inoculating each fungus separately and together to three day old seedlings of the rice variety Kuruluthuda.

\section{Seed germination}

Seeds were surface sterilized as described in 2.2 above. The surface sterilized seeds were soaked overnight in SDW and allowed to germinate by wrapping with a wet cloth for three days at RT $\left(30^{\circ} \mathrm{C}\right)$.

\section{Inoculation of seedlings}

Inoculation of seedlings was carried out using two methods, (a) spore suspension method and (b) plate method.

(a) Spore suspension method:

10 day old cultures of Acremonium and Arthrobotrys grown on PDA plates were used to prepare the spore suspensions. $5 \mathrm{ml}$ of SDW was added to each culture and the spores were dislodged using a sterilized glass spreader. The resulting spore suspensions were transferred to sterilized petri dishes and spore concentrations adjusted to $1 \times 10^{6}$ spores $/ \mathrm{ml}$.

Inoculation of the seedlings was done in the following manner:

(i) Immersion of seedlings in $40 \mathrm{ml}$ of each quantified fungal spore suspension separately in a petri plate.

(ii) Immersion of seedlings in a mixture of $20 \mathrm{ml}$ each of spore suspensions ( $40 \mathrm{ml}$ in total) in a petri plate.

(iii) Immersion of seedlings in $40 \mathrm{ml}$ of SDW in a petri plate (control).

Ten seedlings were used for each treatment and they were immersed in the spore suspensions/SDW overnight at $\mathrm{RT}\left(30^{\circ} \mathrm{C}\right)$.There were ten replicates for each treatment.

(b) Plate method:

10 day old Acremonium and Arthrobotrys cultures grown on PDA were used for the plate method and the inoculation was carried out as follows;

(i) Seedlings were placed on each fungal culture plate separately and incubated for $2-3$ days at RT $\left(30^{\circ} \mathrm{C}\right)$.

(ii) Seedlings were placed on Acremonium culture plates for 2 consecutive days and subsequently on Arthrobotrys culture platesfor 2 consecutive daysat RT $\left(30^{\circ} \mathrm{C}\right)$.

(iii) Seedlings transferred onto PDA+tetracycline plates without the fungus served as the controls.

Ten seedlings were used for each treatment and there were ten replicates for each treatment.

\section{Confirmation of entry and establishment of inocula}

To test whether the inoculations were successful, randomly selected 15 seedlings subjected to each treatment of both methods including controls were surface sterilized (75\% ethanol for $30 \mathrm{~s}, 1 \% \mathrm{NaOCl}$ for $10 \mathrm{~min}$ and $70 \%$ ethanol for $30 \mathrm{~s}$ ) and transferred onto PDA plates supplemented with tetracycline (50 mg. $\left.1^{-1}\right)$.

\section{Determination of the effect on plant growth and yield}

The effect of the endophytes was evaluated under greenhouse conditionas pot experiment and in the field using seedlings inoculated with the fungal species separately and together by both methods of inoculation.

Pot experiments in greenhouse

Fifty seedlings selected randomly from the five replicates of each treatment were washed with SDW and planted in polythene bags $(31 \mathrm{~cm}$ of diameter and $24.4 \mathrm{~cm}$ of height) filled with soil treated with organic fertilizers transported from a paddy field, which had been autoclaved for $20 \min \left(121^{\circ} \mathrm{C}\right.$ and $\left.15 \mathrm{lb}^{-i^{-2}}\right)$. Overall eighty bags were prepared at a rate of five seedlings per bag. Plants were watered regularly and maintained under a temperature range $30^{\circ} \mathrm{C}$ (day) and $20^{\circ} \mathrm{C}$ (night) in the greenhouse for 3 months.

\section{Field trials}

Autoclaved (at $121^{\circ} \mathrm{C}$ and $15 \mathrm{lb}_{\text {.in }}^{-2}$ for $20 \mathrm{~min}$ ) coconut coir was layered on plastic trays $(31 \mathrm{~cm} \times 20 \mathrm{~cm}$ ) and seedlings subjected to each treatment were planted in the trays (150 seedlings per tray). Plants were allowed to grow under greenhouse conditions for 2 weeks with regular watering of the coconut coir. 14 day old plants were introduced into a pre-leveled field prepared for planting and they were hand-planted separating the groups of plants subjected to different treatments according to randomized block design (Fig. 1).

Plants were allowed to grow in the field for 4 months until maturation under controlled conditions:the water depth was maintained evenly at 5 inches with 2 weekly additions of a liquid organic fertilizer mixture supplemented with dolomite (green manure, cow dung and dolomite, 7:2:1). 


\begin{tabular}{|l|l|}
\hline \multicolumn{2}{|c|}{$3.1 \mathrm{~m}$} \\
\hline 1 & 2 \\
\hline 3 & 4 \\
\hline 2 & $\mathbf{N}$ \\
\hline 4 & 3 \\
\hline 1 & 2 \\
\hline 3 & 4 \\
\hline 4 & 1 \\
\hline 2 & 3 \\
\hline
\end{tabular}

1 Acremonium inoculation

2 Arthrobotrys inoculation

3 Inoculation with both fungal isolates

4 Control

Figure 1. Lay out of the field trials.

\section{Parameters Evaluated}

Height, fresh and dry weights of the plants under greenhouse and field conditions were measured for each treatment separately at 2 weeks, 4 weeks and 10 weeks after planting. The length of the crown to the end point of the flag leaf was measured as plant height. Dry weight of the plant was measured by oven drying at $60^{\circ} \mathrm{C}$ until a constant weight was reached. Number of tillers per plant of the plants grown under field conditions was measured at the panicle initiation stage (10 weeks after planting). Weight of the seeds per plant was measured at harvesting stage. The results were analyzed statistically using ANOVA and pair wise comparisons of treatments were done using T-test.

\section{RESULTS}

\section{Microscopic observations of endophytic fungi in Kuruluthuda}
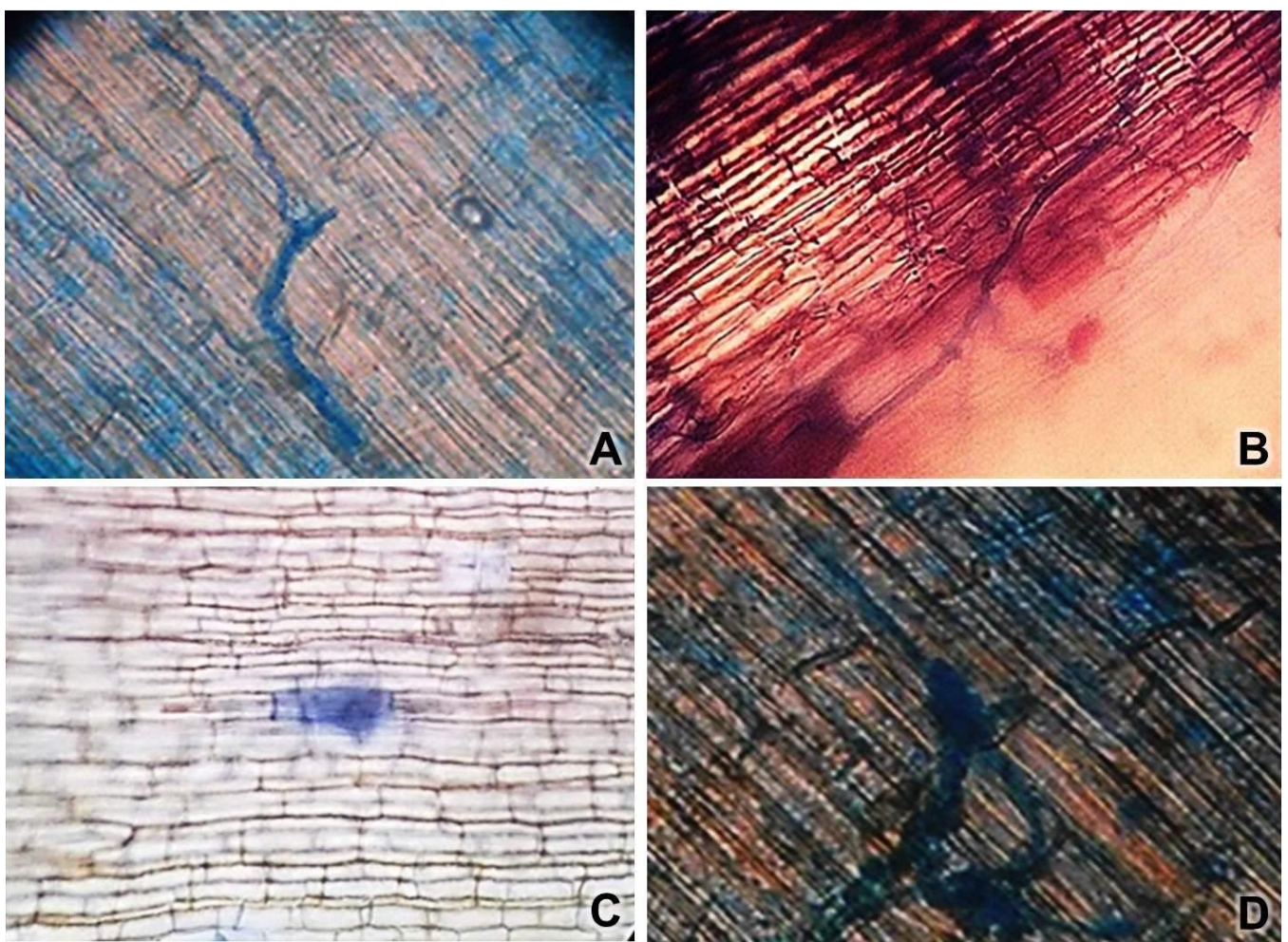

Figure 2. Endophytic fungal structures in Kuruluthuda roots: A-B, Trypan blue stained hyphae of endophytic fungal species $(10 \times 40 \times 2)$; C-D, Sclerotium-like structures of colonized endophytic fungi $(10 \times 40 \times 3)$. 
Root segments stained withtrypan blue were examined for the presence of endophytic fungal structures. Intra and intercellular hyphae were seen in the root cortex parallel to the longitudinal axis of the roots (Fig. 2A \& B), and intra-cellular, sclerotium-like structures were observed in roots (Fig. 2C \& D).

Table 1. Occurrence of endophytic fungi in different parts of Kuruluthuda plants.

\begin{tabular}{lrrr}
\hline Plant part & $\begin{array}{r}\text { Total number of } \\
\text { samples }\end{array}$ & $\begin{array}{r}\text { Number of fungal } \\
\text { species isolated }\end{array}$ & $\begin{array}{r}\text { Percentage frequency of } \\
\text { isolation }\end{array}$ \\
\hline Root & 25 & 13 & 52 \\
Stem & 25 & 6 & 24 \\
Leaf & 25 & 5 & 24 \\
seed & 25 & 3 & 12 \\
\hline Total & 125 & 27 & 21.6 \\
\hline
\end{tabular}

Note: Fungi isolated from surface sterilized plant parts placed on MEA plates. There were 25 replicates for each plant part.

\section{Isolation and identification of endophytic fungi from Kuruluthuda rice variety}

A total of 27 endophytic fungi were isolated from 125 samples of root, stem, leaf and seeds of plants of Kuruluthuda assessed. Endophytic fungi were isolated at a higher frequency from root segments (Table 1). Acremonium, Arthrobotrys, Colletotrichum and Humicola showed ubiquitous colonization as they were isolated at least from 3 different plant parts and Acremonium was the most dominant endophytic fungus present in Kuruluthuda (Table 2).

Table 2. Dominant endophytic fungal percentage and their colonized plant part of Kuruluthuda.

\begin{tabular}{|c|c|c|}
\hline Endophytic fungi & Colonized plant part & Percentage dominance \\
\hline Acremonium & seed, stem, leaf & 60.0 \\
\hline Arthrobotrys & root, stem, leaf & 38.6 \\
\hline Aspergillus sp1 & root & 10.4 \\
\hline Aspergillus sp2 & root & 20.8 \\
\hline Aureobasidium & root & 0.8 \\
\hline Chaetomium & root & 10.4 \\
\hline Colletotrichum & stem, leaf, seed & 26.4 \\
\hline Curvularia & root & 13.6 \\
\hline Fusarium & seed & 3.2 \\
\hline Humicola & root, stem, leaf & 33.6 \\
\hline Penicillium sp1 & root & 6.4 \\
\hline Penicillium sp2 & stem & 8.0 \\
\hline Phoma sp1 & root & 8.0 \\
\hline Phoma sp2 & stem & 4.8 \\
\hline Rhizoctonia & leaf & 0.8 \\
\hline Rhizopus sp1 & stem & 4.0 \\
\hline Trichoderma sp1 & root & 5.6 \\
\hline Trichoderma $\mathrm{sp} 2$ & root & 1.6 \\
\hline Unidentified genus 1 & root & 13.6 \\
\hline Unidentified genus 2 & root & 8.8 \\
\hline Sterile Mycelia (SM) 1 & stem & 4.0 \\
\hline SM 2 & root & 0.8 \\
\hline SM 3 & root & 2.4 \\
\hline SM 4 & leaf & 4.8 \\
\hline SM 5 & root, leaf & 9.6 \\
\hline SM 6 & seed & 0.8 \\
\hline
\end{tabular}

\section{Effectiveness of the methods used for endophyte inoculation to rice seedlings}

Two of the most frequently isolated fungal endophytes i.e. Acremonium and Arthrobotrys were inoculated to seedlings separately and in combination to test their effect on the growth and productivity of the rice variety 
Kuruluthuda using spore suspension and plate methods. To test for successful entry and colonization of seedlings, re-isolations were carried out. Fungal species identical to those that were inoculated were re-isolated from the seedlings inoculated using both methods. The inoculated fungal species were not isolated from the noninoculated seedlings treated with SDW (controls). These results confirmed that both methods of inoculation of the endophytes into seedlings were successful.
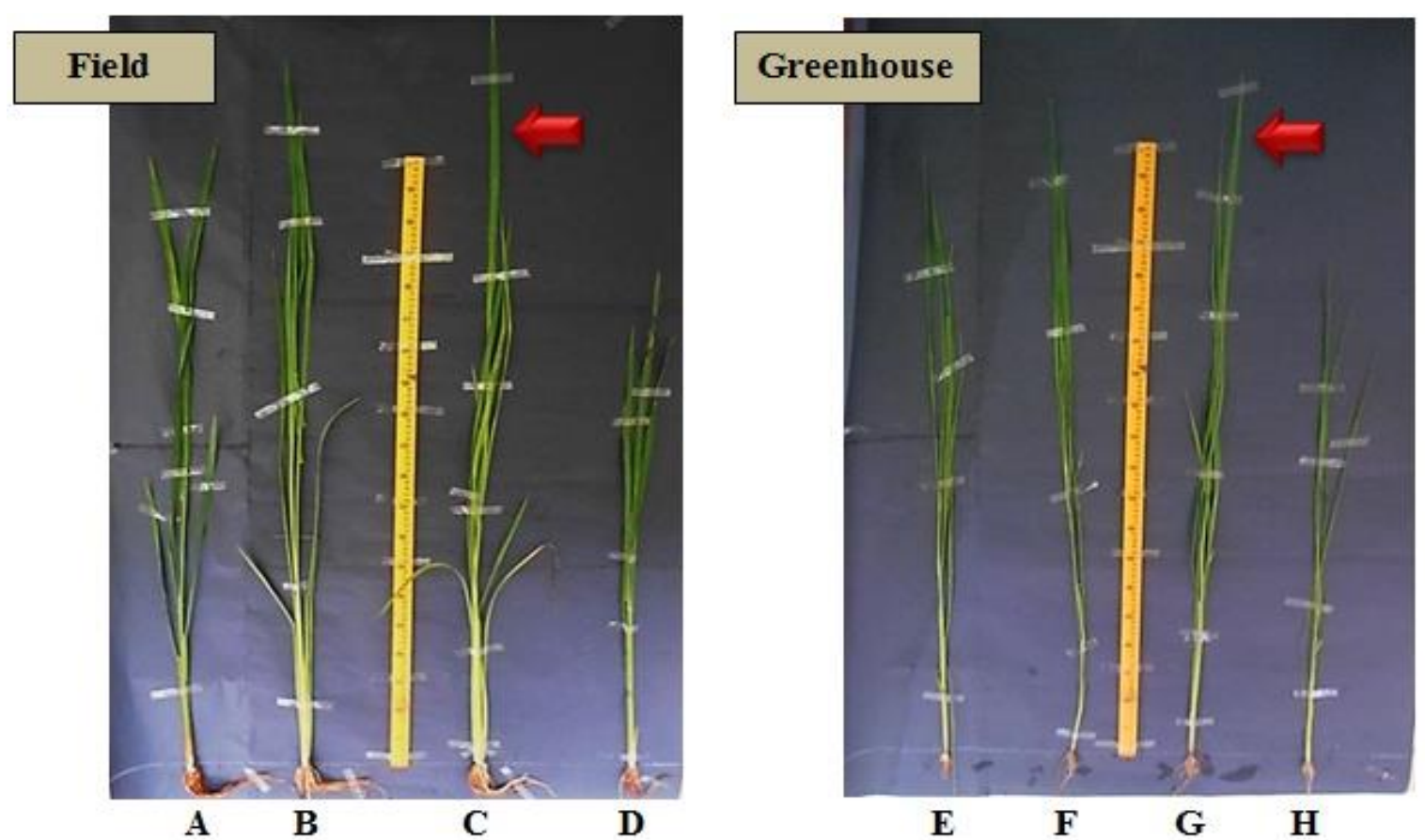

Figure 3. Variation in shoot length after 10 weeks: A-D, Kuruluthuda plants grown under field conditions; E-H, Kuruluthuda plants grown under greenhouse conditions; A,E, Acremonium inoculated plants; B,F, Arthrobotrys inoculated plants; C,G, Acremonium\&Arthrobotrys inoculated plats; D,H, non-inoculated plants. Plants inoculated with both endophytic fungi show a significant increase of plant height (arrowed).

\section{Effect of Acremonium and Arthrobotrys on growth and yield of Kuruluthuda}

A significant difference $(\mathrm{P} \leq 0.05)$ in plant height as well as fresh and dry weights was observed for the plants subjected to all 3 treatments (i. Acremonium inoculation, ii. Arthrobotrys inoculation, iii. Acremonium and Arthrobotrys combined inoculation) when compared with non-treated plants under both field and greenhouse conditions after two, six and ten weeks (Table 3,4 \& 5) (Fig 3). Plant height, fresh weight and dry weight of all treated and non-treated plants increased with time up to 10 weeks and finally became constant at panicle initiation stage.

Table 3. Effect of endophyte inoculation on plant height 2, 6 and 10 weeks after planting.

Mean plant height $(\mathbf{c m}) \pm$ SE

\begin{tabular}{|c|c|c|c|c|c|c|}
\hline \multirow{3}{*}{ Treatment } & \multicolumn{6}{|c|}{ Mean plant height $(\mathrm{cm}) \pm \mathrm{SE}$} \\
\hline & \multicolumn{2}{|c|}{ After 2 weeks } & \multicolumn{2}{|c|}{ After 6 weeks } & \multicolumn{2}{|c|}{ After 10 weeks } \\
\hline & Field & Greenhouse & Field & Greenhouse & Field & Greenhouse \\
\hline Acremonium inoculation & $18.7 \pm 0.28^{\mathrm{a}}$ & $17.9 \pm 0.37^{\mathrm{a}}$ & $71.8 \pm 0.98^{\mathrm{a}}$ & $64.9 \pm 1.44^{\mathrm{a}}$ & $106.0 \pm 1.21^{\mathrm{a}}$ & $93.6 \pm 2.03^{\mathrm{a}}$ \\
\hline Arthrobotrys inoculation & $18.5 \pm 0.38^{a}$ & $19.1 \pm 0.50^{\mathrm{a} b}$ & $79.5 \pm 0.91^{\mathrm{b}}$ & $78.5 \pm 1.64^{\mathrm{ab}}$ & $113.7 \pm 0.74^{\mathrm{b}}$ & $108.5 \pm 1.93^{\mathrm{b}}$ \\
\hline $\begin{array}{l}\text { Acremonium \& } \\
\text { Arthrobotrys inoculation }\end{array}$ & $19.2 \pm 0.37^{\mathrm{a}}$ & $20.0 \pm 0.45^{\mathrm{b}}$ & $81.6 \pm 1.01^{\mathrm{b}}$ & $84.0 \pm 0.90^{\mathrm{b}}$ & $117.1 \pm 0.84^{b}$ & $110.2 \pm 1.88^{b}$ \\
\hline Non inoculation & $14.5 \pm 0.32^{b}$ & $14.3 \pm 0.41^{\mathrm{c}}$ & $58.3 \pm 0.93^{\mathrm{c}}$ & $51.0 \pm 1.16^{\mathrm{c}}$ & $98.3 \pm 0.84^{\mathrm{c}}$ & $73.6 \pm 1.24^{\mathrm{c}}$ \\
\hline
\end{tabular}

Note: $n=20$; mean \pm SE; Mean values sharing common letters in each row are not significantly different $p \leq 0.05$.

Plants inoculated with Arthrobotrys showed a significant difference $(\mathrm{P} \leq 0.05)$ in plant height, fresh weight, dry weight, tiller number and yield compared to the plants inoculated with Acremonium (Table 3,4,5,6 \& 7) (Fig 3 A,B \& E,F). There was a significant difference $(\mathrm{P} \leq 0.05)$ in fresh and dry weights in plants inoculated with both fungal species separately and in combination in both greenhouse and field trials as compared with noninoculated plants. This was shown as early as 6 weeks (Table $4 \& 5)$. There was no significant difference $(\mathrm{P} \leq$ 0.05 ) in plant height and in tiller number between Arthrobotrys single inoculation and combined inoculation of both fungal species. However it was significantly different $(\mathrm{P} \leq 0.05)$ when compared to Acremonium www.tropicalplantresearch.com 
inoculated plants after 6 and 10 weeks of planting (Table $3 \&$ 6). Combined effect of two endophytic fungi showed an increase of the fresh weight and dry weight than their individual effects after 6 and 10 weeks of planting (Table 4 \& 5).

Table 4. Effect of endophyte inoculation on fresh weight 2, 6 and 10 weeks after planting.

\begin{tabular}{|c|c|c|c|c|c|c|}
\hline \multirow{3}{*}{ Treatment } & \multicolumn{6}{|c|}{ Mean fresh weight $(\mathrm{g}) \pm \mathrm{SE}$} \\
\hline & \multicolumn{2}{|c|}{ After 2 weeks } & \multicolumn{2}{|c|}{ After 6 weeks } & \multicolumn{2}{|c|}{ After 10 weeks } \\
\hline & Field & Greenhouse & Field & Greenhouse & Field & Greenhouse \\
\hline Acremonium inoculated & $0.28 \pm 0.01^{\mathrm{a}}$ & $0.18 \pm 0.02^{\mathrm{a}}$ & $3.41 \pm 0.98^{\mathrm{a}}$ & $1.71 \pm 0.38^{\mathrm{a}}$ & $7.25 \pm 0.22^{\mathrm{a}}$ & $5.20 \pm 019^{a}$ \\
\hline Arthrobotrys inoculated & $0.39 \pm 0.02^{\mathrm{b}}$ & $0.20 \pm 0.02^{\mathrm{a}}$ & $3.85 \pm 0.78^{\mathrm{b}}$ & $1.82 \pm 0.51^{\mathrm{b}}$ & $7.86 \pm 0.20^{\mathrm{b}}$ & $5.25 \pm 022^{\mathrm{a}}$ \\
\hline $\begin{array}{l}\text { Acremonium \& Arthrobotrys } \\
\text { inoculated }\end{array}$ & $0.40 \pm 0.03^{b}$ & $0.21 \pm 0.02^{\mathrm{a}}$ & $4.21 \pm 0.53^{c}$ & $2.15 \pm 0.48^{c}$ & $9.31 \pm 0.19^{c}$ & $5.74 \pm 013^{b}$ \\
\hline Non inoculated & $0.13 \pm 0.01^{\mathrm{c}}$ & $0.08 \pm 0.01^{\mathrm{b}}$ & $2.24 \pm 0.37^{\mathrm{d}}$ & $1.14 \pm 0.36^{\mathrm{d}}$ & $6.24 \pm 0.12^{\mathrm{d}}$ & $3.87 \pm 0.17^{\mathrm{c}}$ \\
\hline
\end{tabular}

Note: $n=20$; mean \pm SE; Mean values sharing common letters in each row are not significantly different $p \leq 0.05$.

Table 5. Effect of endophyte inoculation on dry weight 2, 6 and 10 weeks after planting.

\begin{tabular}{|c|c|c|c|c|c|c|}
\hline \multirow{3}{*}{ Treatment } & \multicolumn{6}{|c|}{ Mean dry weight $(g) \pm S E$} \\
\hline & \multicolumn{2}{|c|}{ After 2 weeks } & \multicolumn{2}{|c|}{ After 6 weeks } & \multicolumn{2}{|c|}{ After 10 weeks } \\
\hline & Field & Greenhouse & Field & Greenhouse & Field & Greenhouse \\
\hline Acremonium inoculated & $0.049 \pm 0.002^{\mathrm{a}}$ & $0.034 \pm 0.002^{\mathrm{a}}$ & $1.095 \pm 0.23^{\mathrm{a}}$ & $0.478 \pm 0.02^{\mathrm{a}}$ & $2.478 \pm 0.05^{\mathrm{a}}$ & $1.115 \pm 0.05^{\mathrm{a}}$ \\
\hline Arthrobotrys inoculated & $0.050 \pm 0.003^{\mathrm{a}}$ & $0.050 \pm 0.02^{\mathrm{b}}$ & $1.214 \pm 0.16^{\mathrm{b}}$ & $0.584 \pm 0.035^{\mathrm{a} b}$ & $2.707 \pm 0.021^{\mathrm{b}}$ & $1.244 \pm 0.036^{\mathrm{b}}$ \\
\hline Acremonium \& & $0.052 \pm 0.003^{\mathrm{a}}$ & $0.055 \pm 0.02^{\mathrm{b}}$ & $1.586 \pm 0.12^{\mathrm{c}}$ & $0.748 \pm 0.11^{\mathrm{c}}$ & $3.421 \pm 0.002^{\mathrm{c}}$ & $1.586 \pm 0.01^{\mathrm{c}}$ \\
\hline Arthrobotris inoculated & & & & & & \\
\hline Non inoculated & $0.030 \pm 0.001^{\mathrm{b}}$ & $0.014 \pm 0.001^{\mathrm{c}}$ & $0.894 \pm 0.08^{\mathrm{d}}$ & $0.361 \pm 0.013^{\mathrm{d}}$ & $1.987 \pm 0.04^{\mathrm{d}}$ & $0.758 \pm 0.02^{\mathrm{d}}$ \\
\hline
\end{tabular}

Note: $n=20$; mean \pm SE; Mean values sharing common letters in each row are not significantly different $p \leq 0.05$.

A significant difference $(\mathrm{P} \leq 0.05)$ in tiller number and yield per plant was observed in the plants subjected to all 3 treatments compared with non-treated plants under field conditions (Table $6 \& 7$ ). Combined inoculation of Acremonium and Arthrobotrys showed an increase of yield than the plants subjected to other two treatments (Table 7). However data indicated that the overall effect of Arthrobotrys was higher than that of Acremonium. There was no significant difference in plant height between plants grown under greenhouse and field condition but the fresh weight and dry weight increased in all treated and non-treated plants under field condition when compared to greenhouse condition (Table 3).

\begin{tabular}{lr} 
Table 6. Mean number of tillers at panicle initiation stage. (After10 weeks of planting) \\
\hline Treatment & Mean number of tillers \pm SE \\
\hline Acremonium inoculated & $5.5 \pm 0.14^{\mathrm{a}}$ \\
Arthrobotrys inoculated & $6.0 \pm 0.14^{\mathrm{b}}$ \\
Acremonium \& Arthrobotrys inoculated & $7.3 \pm 0.16^{\mathrm{b}}$ \\
Non inoculated & $4.6 \pm 0.11^{\mathrm{c}}$ \\
\hline
\end{tabular}

Note: $n=20$; mean of tillers \pm SE; mean values that do not share a letter are significantly different $p \leq 0.05$.

Table 7. Mean yield/plant (g) of Kuruluthuda variety. (After 12 weeks)

\begin{tabular}{lr}
\hline Treatment & Mean yield per plant $(\mathbf{g}) \pm \mathbf{S E}$ \\
\hline Acremonium inoculated & $5.99 \pm 0.12^{\mathrm{a}}$ \\
Arthrobotrys inoculated & $7.57 \pm 0.12^{\mathrm{b}}$ \\
Acremonium \& Arthrobotrys inoculated & $9.65 \pm 0.23^{\mathrm{c}}$ \\
Non inoculated & $4.54 \pm 0.17^{\mathrm{d}}$ \\
\hline
\end{tabular}

Note: $n=20$; mean of yield/plant \pm SE; mean values that do not share a letter are significantly different $\mathrm{p} \leq 0.05$. The mean weight of seeds per plant is considered as yield.

\section{DISCUSSION}

There is renewed interest in the cultivation of traditional rice varieties using organic farming practicesin Sri Lanka due to numerous health problems such as the Chronic Kidney Disease of Unknown Etiology (CKDU) which is spreading fast amongst farmers in the country as well as various environmental problems. The traditional rice varieties, whilst responding well to organic cultivation practices, produce low yields and thus, finding means of yield improvementis important. Research based on the development of effective organic fertilizers consisting of applicable microorganism preparations for increased yield is a viable solution to the problem. Endophytic fungi that grow as symbiontsin plants have been reported to enhance growth in a number 
of crops as well as in organic rice cultivation (Angelard et al. 2010). The ability of endophytic fungi to improve plant growth and reduce rice blast incidence in traditional rice varieties of Sri Lanka has also been reported. (Atugala \& Deshappriya 2015, Ponnawila \& Deshappriya 2014).

Therefore, the present study was carried out to test whether fungal endophytes of the Sri Lankan traditional rice variety Kuruluthuda would show a similar capacity for growth and yield enhancement of rice plants under green house and field conditions. Determination of the endophytic association was initialized by isolation of the endophyticfungal assemblage present in different parts of plants of the variety Kuruluthuda. As the use of fresh plant material is a critical requirement for successful isolation, fresh plant samples collected from the field were used for fungal isolations within 48 hours. Direct observation of trypan blue stained squashed root preparations indicated the co-existence of endophytic fungi inside roots without causing apparent damage to plant tissue.

Since the endophytes are a group of microorganisms thatcan spend a part of their life cycle in different parts of the same plant (Petrini et al. 1992), most parts of the plant i.e. roots, stem, leaves and seeds were used for the isolations. A suitable surface sterilization regime is essential to eliminate epiphytic microbes present on the plant surface whilst maintaining the viability of the endophytes. Therefore, the most effective surface sterilizing regimes developed in a previous study (Atugala \& Deshappriya 2015) were used for the effective surface sterilization of the plant parts used for isolations. Once surface sterilized,the plant parts were plated on MEA medium supplemented with tetracycline $(50 \mathrm{mg} / \mathrm{L})$ as soil and endophytic fungi are reported to grow more effectively on MEA resultingin a higher fungal yield and species richness (Bills \& Polishook 1993). Tetracycline added to the medium restrained bacterial growth until emergence of fungal colonies from the plant segment.

Isolation of endophytic fungi from healthy Oryza sativa plants has been reported previously to yield a few fungal genera such as Fusarium, Aspergillus, Curvularia, Penicillium, Gilmaniella and Arthrobotrys foliicola at a high frequency (Zakaria et al. 2010). Most fungal genera isolated from Sri Lankan traditional rice varieties Suwandel and Kaluheenati belonged to the class ascomycetes and they have been identified as being members of commonly observed genera of soil fungi, e.g. Fusarium, Penicillium, Rhizopus, Rhizoctonia, Absidia, Aspergillus and Paecilomyces (Atugala \& Deshappriya 2015). In a comparison of endophytic assemblages between traditional and newly improved rice varieties in Sri Lanka, higher fungal colonization and species richness have been shownby the traditional rice varieties Suwandel and Herath Banda compared to the newly improved variety Bg 352. Fusarium and Arthrobotrys have been identified as the most frequently colonized endophytic fungi in Herath Banda traditional variety (Ponnawila \& Deshappriya 2014). In the present study, 27 different fungal genera wereisolated from the variety Kuruluthuda. However, unlike in the previous studies, the most frequently isolated genera were Acremonium, Arthrobotrys, Colletotrichum and Humicola. Acremonium was mostly isolated from leaf and stem, Arthrobotrys from roots, Colletotrichum from stem and Humicola from leaves. Colonization and isolation frequencies of isolates in each plant part revealed that Kuruluthuda has a rich endophytic fungal diversity that is ubiquitous within the whole plant. Nevertheless, most isolates were restricted to specified areas of the plants. A surprisingly rich endophytic community was associated with roots but Fusarium and sterile mycelia species were restricted only to seeds.

The combined and individual effects of the two most frequently isolated fungal endophytes Acremonium and Arthrobotryson growth and production of variety Kuruluthuda was tested under field and greenhouse conditions. Previous studies have shown that fungal inoculation into immature roots of seedlings was successful when they were in direct contact with fungal cultures (Fischer 1962, Herre et al. 2007) or immersed in a spore suspension (Champion et al. 1973, Abdel-Motaal et al. 2010). In this study, both methods were used and the ability to reisolate the same fungal species from the seedlingsas that of the inoculated species confirmed the success of both spore suspension and plate methods in introducing the endophytes to plant seedlings. This is significant as successful and easy introduction of inoculum into plants is an essential aspect of development of a biofertilizer.

In the present study,endophyte inoculated plants showed a significant increase of plant height, fresh weight and dry weight $(\mathrm{P} \leq 0.05)$ when compared with non-inoculated plants during a 10 week period under both field and greenhouse conditions. These results are in agreement with previous studies carried out in Sri Lanka (Ponnawila \& Deshappriya 2014, Atugala \& Deshappriya 2015) and indicate that rice plant growth can be enhanced by introducing their endophyticmyco flora.

Mechanisms of growth enhancement were not studied in the present study. However evidence from previous studies have indicated that fungal endophytes promote plant growth and performance in a number of ways 
including the production of siderophores, supplying biologically fixed nitrogen and by secretion of plant growth regulators (Herre et al. 2007, Kedar et al. 2014). The endophytic fungi of Potentilla fulgensis is reported to have the metabolic machinery to secrete plant growth hormones such as cytokinins, auxins and gibberellins which promote seed germination and growth (Bhagobaty \& Joshi 2009).

Khan et al. (2015) reported that two fungal endophytes, Fusarium and Alternaria isolated from the leaves of Solanumnigrum, increased the chlorophyll content, root-shoot length, and biomass production of Dongjin rice plantswhen inoculated at the seedling stage. Gas chromatography/ mass spectrometry analysis for the culture filtrates of each fungal endophytic isolate revealed that both Fusarium and Alternaria could produce 54 and 30 $\mu . g m . \mathrm{L}^{-1}$ of indole acetic acid, respectively.

In addition, Kedar et al. (2014) revealed a significant effect on shoot height, root length, fresh and dry weights of shoots and roots of experimental maize plants inoculated with the endophytic fungus Phoma compared to non-inoculated plants. It was also found that the roots of germinated seeds treated with the Phoma extract showed development of additional root hairs allowing the absorption of more nutrients which subsequently resulted in increased growth and biomass of plants.

Based on these reports, it can be concluded that endophytes have a number of mechanisms to enhance plant growth and the similar trend of growth enhancement observed in the present study may also be attributed to one or more of such mechanisms.

In most previous studies, individual effects of two endophytic fungi on host plant performances have been tested. Waqas et al. (2012) reported that the endophytic fungi Phomaglomerata and Penicillium sp. significantly promoted the shoot growth of rice as well as increased plant biomass and related growth parameters of cucumber plants compared to non-inoculated plants. However, the combined effect of two endophytes has not been evaluated in these studies. In the present study, the combined effect of two endophytic fungal species showed an increase of the fresh and dry weights when compared with their individual effects on Kuruluthuda plants under both field and greenhouse conditions. It can be concluded that Acremonium and Arthrobotrys may have a synergistic effect that results inimproved plant weight. A significant difference of plant height could not be observed between Arthrobotrys single inoculation and combined inoculation with both fungal species. However, there was a significant increase in the height of plants inoculated with Arthrobotrys when compared with those inoculated with Acremonium indicating that Arthrobotrys might have the ability to improve plant height than Acremonium.

Although tillers of the Kuruluthuda variety were formed 4 weeks after planting, the number of tillers was counted at the panicle initiation stage to obtain an accurate count of tillers per one bush. An increased number of tillers could be observed for the plants inoculated with both fungi. It is reported that endophytic fungi associated with many agricultural crops improve crop production significantly (Yuan et al. 2009). In this study also endophytes inoculated Kuruluthuda plants yielded a significantly higher amount of seeds when compared with non-inoculated plants. Plants inoculated with both Acremonium and Arthrobotrys gave a higher yield as well as improved fresh and dry weights. Therefore it can be concluded that the combination of two endophytic fungi can result in increased biomass and rice yield. These results were evident as early as six weeks after planting and remained to be so uptothe harvesting stage (12 weeks). There was no difference in plant height between plants grown under greenhouse and field conditions but increased fresh weight and dry weight could be observed under field conditions when compared to greenhouse condition. The enhanced effect of endophyte inoculation shown by plants grown under field conditions when compared with those grown under greenhouse conditions was both an interesting and encouraging result.

Based on these very promising results, an inoculum consisting of the two fungal endophytes i.e. Acremonium and Arthrobotrys could be utilized to enhance the biomass and yield of the rice variety Kuruluthuda. Thisis the first report on the endophytic fungal assemblage present in the varietyKuruluthuda and their potential to be used for improved productivity of the rice variety under field conditions. The possibility of developing such an inoculum as a biofertiliser for other rice varieties after more stringent testscould be the solution to the many problems associated with the use of chemical fertilizers in rice cultivation in Sri Lanka and worldwide.

\section{CONCLUSIONS}

- Kuruluthuda traditional rice variety consists of a high diversity of fungal endophytesin most parts of the plant i.e. root, stem, leaf, and seeds. 
- Spore suspension method and plate method can be used for successful inoculation of fungal endophytes into seedling roots.

- Acremonium and Arthrobotrys can improve the growth of rice plants of the variety Kuruluthuda and yield under field conditions.

- Combined effect of the two endophytes enhances the fresh weight, dry weight, number of tillers and yield of rice plants significantly as compared to their effect when inoculated separately.

\section{REFERENCES}

Abdel-Motaal F, Nassar MSM, El-Zayat SA, El-Sayed MA \& Ito S (2010) Antifungal activity of endophytic fungi isolated from Egyptian Henbane (Hyoscyamus muticus L.). Pakistan Journals of Botany 42: 28832894.

Angelard C, Colard A, Niculita-Hizel H, Croll D \& Sanders IR (2010) Segregation in a Mycorrhizal fungus alters rice growth and symbiosis-specific gene transcription. Current biology 20: 1261-1221.

Atugala DM \& Deshappriya N (2015) Effect of endophytic fungi on plant growth and blast diseaseincidence of two traditional rice varieties. Journal of National Science Foundation Sri Lanka 43: 173-187.

Barraquio WL, Revilla L \& Lodha JK (1997) Isolation of endophytic diazotrophic bacteria from wetland rice. Plant and Soil 194: 15-24.

Bhagobaty RK \& Joshi SR (2009) Promotion of seed germination of Green gram and Chick pea by Penicillium verruculosum RS7PF, a root endophytic fungus of Potentilla fulgens L. Advanced Biotech 8(7): 16-18.

Bills GF \& Polishook JD (1993) Abundance and diversity of microfungi in leaf litter of a lowland rain forest in Costa Rica. Mycologia 86: 187-198.

Champion MR, Brunet D, Mauduit ML \& Ilami R (1973) Methods for testing the resistance of bean varieties to anthracnose (Collectotrichum lindemuthianum. And Magn.) Briosi and Cav.P.C.R.Seances acad. Agricultural Food Reaschers 59: 951.

Contreras-Cornejo HA (2009) Trichoderma virens, a plant beneficial fungus enhances biomass production and promotes lateral root growth through an auxin-dependent mechanism in Arabidopsis. Plant Physiology 149: 1579-1592.

Domsch KH, Dams W \& Anderson PL (1993) Compendium of soil fungi, IHW- Verlag press, Berlin, Germany. FAO (1994) Rice Production. Food and Agriculture Organization of the United Nations Year Book 47: 70-71.

Feng QL, Chen GH, Cui FZ, Kim TN \& Kim JO (2000) A mechanistic study of the antibacterial effect of silver ion on E. coli and S. aureus. Journals of Biomedical Materials research 52: 662-668.

Fischer GW (1962) Induced by hybridization and point of inoculation on the symptomatology of barley covered smut. Phytopathology 1962: 52.

Fisher PJ \& Petrini O (1991) Fungal saprobes and pathogens as endophytes of rice (Oryza sativa L.). New Phytology 120: 137-143.

Goveas SW, Madtha R, Nivas SK \& D'Souza L (2011) Isolation of endophytic fungi from Coscinium fenestratum- a red listed endangered medicinal plant. EurAsian journal of BioSciences 5: 48-53.

Herre EA, Mejia LC, Kyllo DA, Rojas E, Maynard Z, Butler L \& Van bael SA (2007) Ecological implications of anti-pathogen effects of tropical fungal endophytes and mycorrhizae. Ecology 88 (3): 550-558.

Kedar A, Rathod D, Yadav A, Agarkar G \& Rai M (2014) Endophytic Phoma sp. isolated from medicinal plants promotes the growth of Zea mays. Bioscience 6: 132-139.

Khan AR, Ullah I, Waqas M, Shahzad R, Hong S, Park G, Jung BK, Lee I \& Shin J (2015) Plant growthpromoting potential of endophytic fungi isolated from Solanum nigrum leaves. World Journal of Microbiology and Biotechnology 31(9): 1461-1466.

Montesinos E (2003) Plant-associated microorganisms: a view from the scope of microbiology. International Microbiology 6: 221-223.

Naik BS, Shashikala J \& Krishnamurthy YL (2009) Study on the diversity of endophytic communities from rice (Oryza sativa L.) and their antagonistic activities in vitro. Microbiological Research 164: 290-296.

Petrini O (1991) Evaluation of fungal endophytes in aerial roots of Ficus benghalensis. Fungal Ecology 17: $175-187$.

Petrini O, Sieber TN, Toti L \& Viret O (1992) Ecology, metabolite production and substrate utilization in endophytic fungi. Natural Toxins 1: 185-196. 
Ponnawila PVAR \& Deshappriya N (2014) Investigation of fungal endophytes present in rice varieties Bg 352, Suwandel and Herath Banda. Proceedings $34^{\text {th }}$ annual sessions of Institute of Biology Sri Lanka 34 (2): 45.

Rathnabharathi W (2009) Role of traditional paddy in adaptation to climate change impact. In: Proceedings of the Role of Community in Adaptation to the Climate Change Crisis Workshop, pp. 67-80.

Ryan R.P, Germaine K, Franks A, Ryan DJ \& Dowling DN (2008) Bacterial endophytes: recent developments and applications. FEMS Microbiology Letters278: 1-9.

Strobel G (2003) Endophytes as sources of bioactive products. Microbes and Infection 5: 535-544.

Tarafdar JC \& Claassen N (1998) Organic phosphorous compounds as a phosphorous source of higher plants through the activity of phosphatase produced by plant roots and microorganisms. Biology and Fertility of soils 5: 308-312.

Tian XL, Cao LX, Tan HM, Zeng QG, Jia YY \& Han WQ (2004) Study on the communities of endophytic fungi and endophytic actinomycetes from rice and their antipathogenic activities in vitro. World Journal of Microbiology and Biotechnology 20: 303-309.

Tutte J (1969) Plant Pathologiacal Methods: Fungi and Bacteria. Burgess Publishing Company, USA, pp. 220.

Waqas M, Khan AL, Kamran M,Hamayun M, Kang S, Kim Y \& Lee J (2012) Endophytic Fungi Produce Gibberellins and Indole Acetic Acid and Promotes Host-Plant Growth during Stress. Molecules 17: 1075410773.

You YH, Yoon H, Kang SM, Shin JH, Choo YS, Lee IJ, Lee JM \& Kim JG (2012) Fungal diversity and plant growth promotion of endophytic fungi from six halophytes in Sun cheon Bay. Journal of Microbiology and Biotechnology 22: 1549-1556.

Yuan Z, Zhang C, Lin F \& Kubicek CP (2009) Identity, diversity, and molecular phylogeny of the endophytic mycobiota in the roots of rare wild rice (Oryza granulate) from a nature reserve in Yunnan, China. Applied and Environmental Microbiology 76: 1642-1652.

Zakaria L, Yaakop AS, Salleh B \& Zakaria M (2010) Short communication: endophytic fungi from paddy. Tropical Life Sciences Research 21: 101-107. 